\title{
Integrating Scientific Inquiry Learning into Project Course of Vocational High Schools to Construct and Verify Core Competency Indicators
}

\author{
Chin-Wen Liao, Yu-Cheng Liao, Yao-Tsung Chiang, Hui-Fen Wu, and Yun-Hua Liao
}

\begin{abstract}
The study aims to construct competence indicators by integrating inquiry-based learning into students' project study at vocational high schools. Based on the competence indicators constructed, students' competence is verified. The study adopts Delphi technique to consult opinions and suggestions from Delphi technique experts. After three rounds of repeated revision, combination, adding and deleting of questionnaire items, the "core competence indicators with the integration of inquire-based learning into students' project study at vocational high schools" are constructed by the analysis of mode, means, standard deviation, Kolmogorov-Smirnov one sample test, and AHP with the consistency of expert opinions as well as level of importance. The competence indicators questionnaire were distributed to 255 students of the 102 academic year, to analyze the importance and IPA, and then to analyze and discuss expert weight with students' perceptions and IPA.
\end{abstract}

Index Terms-Scientific inquiry learning, project course, core competency indicators.

\section{INTRODUCTION}

Recently, many new policies indicated the importance of project study in vocational education. In 2002, the Ministry of Education published White Paper on Creative Education. It indicated, "To meet the challenge of knowledge-based economies, the enhancement of creativity is now more than ever becoming an increasingly important national goal in Taiwan.” Also, White Paper on Scientific Education, which published by the Ministry of Education in 2003, stated that science education is featured on the training of "science literacy". With scientific inquiry activities, students can gain related knowledge and skill, form the habit of scientific thinking, adopt scientific method to demonstrate theories and solve problems by scientific knowledge. The final goal is to make students form understanding toward the core of science and establish scientific spirits. In December of 2013, White Paper on Human Resource Development developed a

Manuscript received April 20, 2015; revised June 29, 2015. This work was supported in part by the Ministry of Science and Technology under Grants MOST 103-2511-S-018-018.

C.-W. Liao, Y.-T. Chiang, and H.-F. Wu are with the Department of Industrial Education and Technology, National Changhua University of Education (NCUE), Taiwan (e-mail: tcwliao@cc.ncue.edu.tw, cytsung@gmail.com,w3313529@gmail.com).

Y.-C. Liao is with the Department of Electrical Engineering, Nationa Taiwan University of Science and Technology, Taiwan (e-mail: ms0605521@yahoo.com.tw).

Y.-H. Liao is with the Department of Civic Education and Leadship, National Taiwan Normal University, Taiwan (e-mail: grapesherry@yahoo.com.tw). blueprint for national talent cultivation with the subject: "transformation and breakthrough, "in hope that the government could have a whole new thought on the issue of cultivation of talent.

Bybee stated that inquiry-based learning contains three main parts [1]. First, it develops students' scientific inquiry competences. Second, it makes students understand the nature of scientific inquiry. Third, it helps students acquire science knowledge. Scientific inquiry is a student-centered learning. Through it, students establish scientific concepts, foster abilities and understand the nature of science.[2], [3].

National Research Council defined scientific inquiry as follows, "Scientific inquiry refers to the diverse ways in which scientists study the natural world and propose explanations based on the evidence derived from their work [3]. Inquiry also refers to the activities of students in which they develop knowledge and understanding of scientific ideas, as well as an understanding of how scientists study the natural world." This definition implied that "how to learn" and "learn how to learn" are major issues in scientific inquiry-based learning.

\section{LITERATURE REVIEW}

\section{A. Definition of Creativity}

Dasgupta indicated that creativity can be shown in different learning situations and different subjects [4]. Despite people from different cultural backgrounds have differences in creativity, in an ideal situation, every people have the potential to show their great creativity [5]. Csikszentmihalyi suggested that creativity must be developed in a specific professional area [6]. The production of creation should be based on specialized knowledge in a domain.

\section{B. Technology Creativity Indicators}

Yeh found that the more aggressive the student's learning attitudes are, the better the academic achievement will be [7]. To foster students' creativity, a teacher should fully understand individual difference which affects students' creative performances [8]. Barak \& Goffer suggested that creative problem-solving is an integral component of technology education in schools [9]. Also, Wu stated that in the education of technical field in vocational schools, learning creative thinking and creative problem solving are as important as learning scientific knowledge and skills [10].

\section{The Learning Theory of Creative Problem Solving}

Sylwester reported that to learn problem solving, the specific practice is to induce students to build on their current 
knowledge and skills, encourage them to build their own knowledge system [11], value narrative messages. Also, a teacher's guidance can foster students' creativity [12].

Khan noted that to learn under context and through facing problems directly is the only way for a learner to acquire a clear understanding toward tasks [13]. Through reflective thinking and interpersonal communication, the learner constructs knowledge actively to solve current problems. Problem-based learning emphasizes on the connection between learning materials and the real world. Through learning in an authentic context, students realize what they learned deeply and gain hands-on experience, which helps them apply what they learned to real life situations. Gardner invented Theory of Multiple Intelligences, which identified eight intelligences: linguistic, logical - mathematical, bodily kinesthetic, visual- spatial, musical-rhythmic, interpersonal, intrapersonal, and naturalistic [14]. As the current education focuses more on linguistics and mathematics, how to assimilate creative problem solving into current curriculum will be an important issue to improve learning outcomes.

\section{Inquiry-Based Learning}

The concept of inquiry is a major factor in science education reform [15]-[17]. Shulman stated that practicing inquiry-based learning based on different classroom contexts is a good try to help students. Teachers should work hard on making a friendly learning environment for students to do inquiry. The experience of inquiry-based learning can generate students' interests in science [18]. This way of learning is active. Abd-El-Khalick \& Lederman also suggested that explicit teaching method, through drill and peer discussion, can make students reflect on the core of scientific inquiry. In this way, students not only achieve scientific inquiry learning and learning goals, they are also encouraged to ask and answer science-related questions [15]-[20].

Brown stated that knowledge is not established on the result. However, it is a dynamic process of inquiry which established on uncertainty, conflict and doubt. Students can be motivated to acquire knowledge actively by providing a rich learning environment suitable for inquiry [21]. Gordin and Pea pointed out three goals students can achieve from inquiry in science education: 1) learning how to pose researchable questions, 2) learning how to investigate questions using authentic practice, 3) developing a deeper understanding toward science [22]. Most teachers consider inquiry as an important element in science education. After experiencing the scientific inquiry process, students can understand the nature of science. The main point of inquiry-based learning is making students understand the nature of scientific inquiry through the training of scientific inquiry activity and scientific inquiry skills. Relative researches also proved that students can acquire a better understanding toward the context and process of science through inquiry-based learning.

\section{RESEARCH METHODS}

\section{A. Documentary Analysis}

The researcher first collects pertinent literature, periodical, theses and dissertations according to research purpose.
Second, through documentary analysis, gain thorough understanding toward the history of curriculum development of vocational education in Taiwan and the current state of project study. Third, investigate related theories, for example, social constructivist theory, theory of inquiry-based learning, cooperative learning theories and project-based learning. Relative researches about project study in vocation high school are also investigated. Afterward, based on the discussed research, initial competence indicators were investigated.

\section{B. Delphi Method}

Delphi Method is used to construct competence indicators by integrating inquiry-based learning into students' project study at vocational high schools initially. By Delphi technique, the items of competence indicators on integrating inquiry-based learning into students' project study at vocational high schools are developed. Later, the study has urged 19 experts, including scholars who have specialized in inquiry-based learning and project development and practitioners who have extensive experience in project practice, to form a Delphi Expert Group to conduct a three-round Delphi survey of experts in order to obtain the consensus of all the experts and scholars. Furthermore, the core competence indicators are modified according to the advice provided by the experts.

\section{Analytic Hierarchy Process}

Through Analytic Hierarchy Process (AHP), the weight distribution of scale items in decided. AHP is a decision making method to systemize complex problems. It is mainly applied in uncertain situations and to solve Multi-criteria decision-making problems. Through Delphi Method and Hierarchy Analysis, the weight is calculated, which boosts analysis objectivity and accuracy [23].

\section{Survey Techniques}

Based on the result of documentary analysis and Delphi method, a Likert-scale questionnaire on competence indicators by integrating inquiry-based learning into students' project study at vocational high school is designed. Later, these questionnaires were sent to students who satisfied the two requirements. The first is to be major in vocational high schools, vocational departments attached to senior high schools, or comprehensive high schools. The second is to have the experience of taking the course of project study or participating in related contests.

\section{E. Important-Performance Analysis}

Based on the valid questionnaires obtained, an Important-Performance Analysis is made on "competence indicators by integrating inquiry-based learning into students' project study at vocational high school, including five dimensions: inquiring research questions competence, active inquiring competence, project study demonstration competence, writing project study research report competence and oral presentation and responding to questions competence.

\section{RESEARCH STEPS}

This study aims to develop the competence indicators by 
integrating inquiry-based learning into students' project study at vocational high schools. The scale would be developed based on the ideas and concepts derived from the literature review, and the weight distribution of scale items would be determined by the Delphi survey of experts through analytic hierarchy process. The completed core competence indicators scale is then used as the questionnaire material and sent to the national vocational students majoring in the area of engineering subjects in Taiwan. The results would be verified by the mean, standard deviation and paired sample t test respectively. Important-performance analysis (IPA) of the students would be analyzed and verified as well.

TABLE I: WEIGHT OF IMPORTANCE AND ORDER OF SECOND LEVEL DIMENSIONS AND THIRD LEVEL SUB-INDICATORS

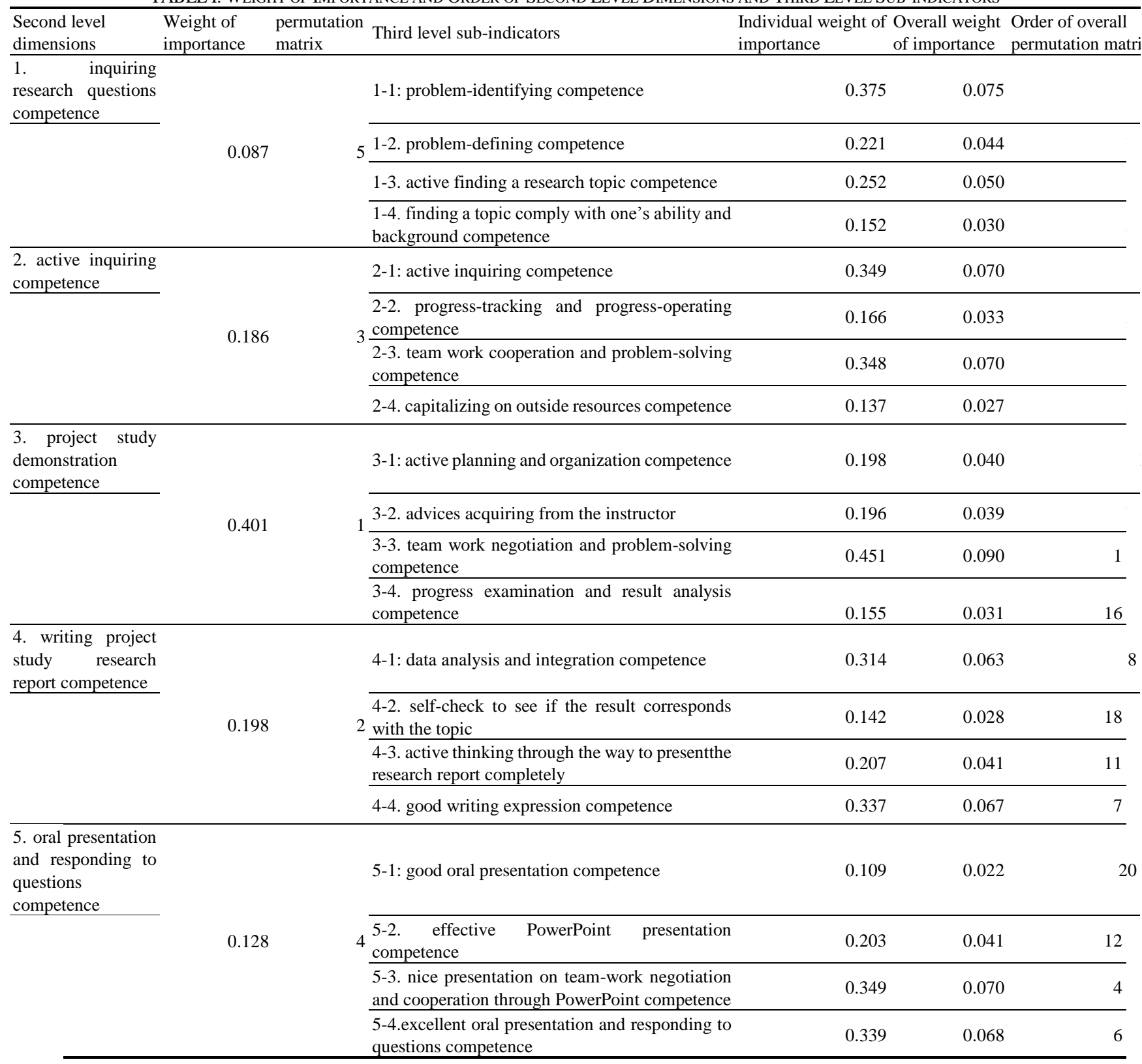

\section{RESEARCH RESULTS AND DISCUSSION}

The core competence indicators are divided into five dimensions: inquiring research questions competence, active inquiring competence, project study demonstration competence, writing project study research report competence and oral presentation and responding to questions competence. In total, there are 20 competence indicator and 79 competence items.

The study first collects and analyzes related literatures domestic and abroad, then modify indicators into AHP questionnaire after experts' examination. Following this, Delphi technique is adopted to consult opinions and suggestions from Delphi technique experts, after going through three rounds of repeated revision, combination, adding and deleting of questionnaire items. Until experts reach a consensus, the "core competence indicators with the integration of inquiry-based learning into students' project study at vocational high schools" is constructed. The results are as follows.

1) The result of Delphi survey of experts has reached consistency.

2) Constructing competence indicators by integrating inquiry-based learning into students' project study at vocational high schools.

The importance level of core competence indicators 
identified by experts according to importance is summarized as follows project demonstration competence is most valued in the first dimension; problem identifying competence, active inquiring competence, team work negotiation and problem-solving competence, good writing expression competence, team-work negotiation and cooperation presented through PowerPoint, excellent oral presentation and responding to questions competence are the most evaluation factors valued by experts.

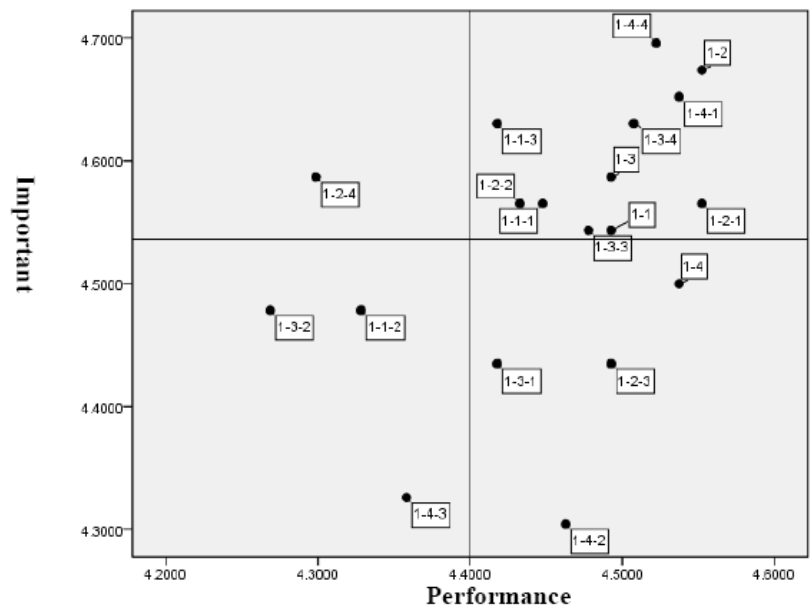

Fig. 1. Inquiring research questions competence.

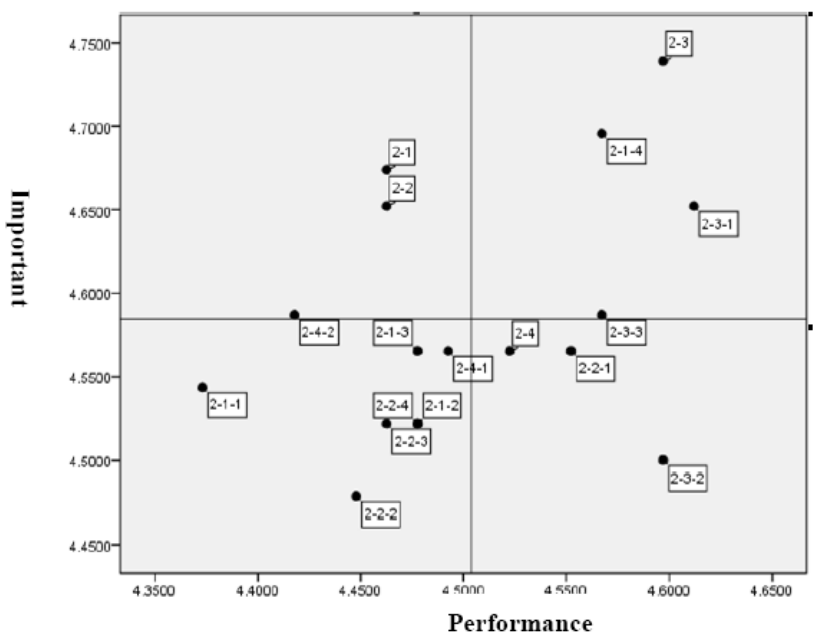

Fig. 2. Active inquiring competence.

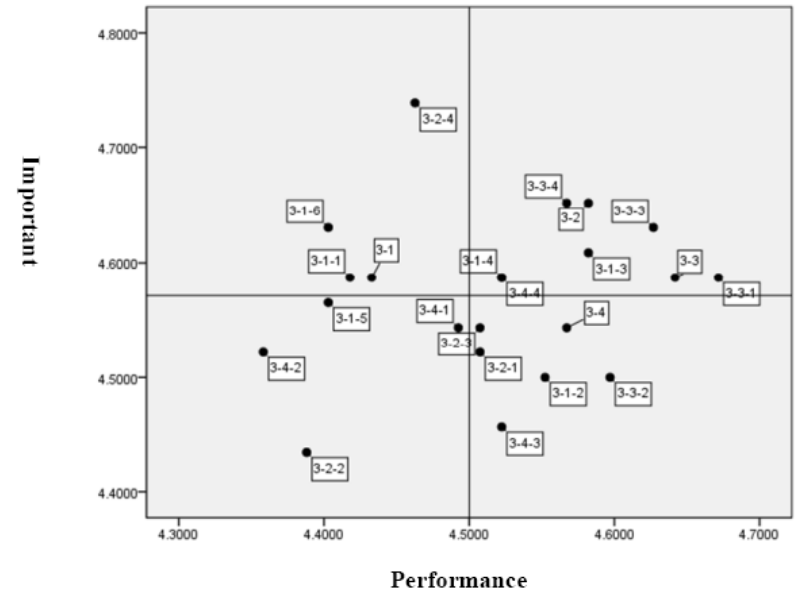

Fig. 3. Project study demonstration competence.

The study adopted Expert Choice 2000 to make statistical analysis with AHP for the questionnaire. The results were suggested as follows. First of all, based on Expert Choice
2000 , the results showed high consistency in the answers. The consistency rate has to fall on $\mathrm{C} . \mathrm{R} \leq 0.1$. It was indicated that the present study's consistency rates were all below 0.1 in terms of indicator dimensions, contents of indicators and indicator items. Second, the importance level of core competence indicators identified by experts according to importance is as follows.

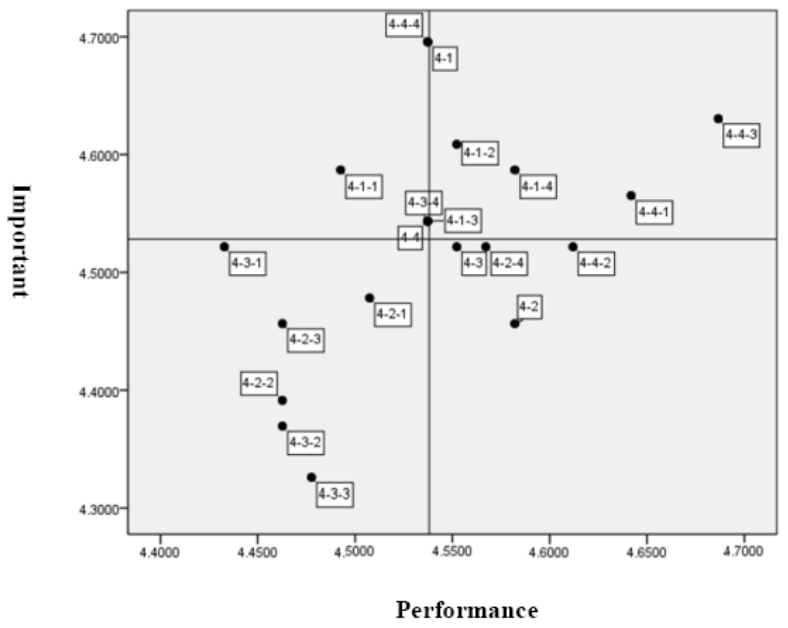

Fig. 4. Writing project study research report competence.

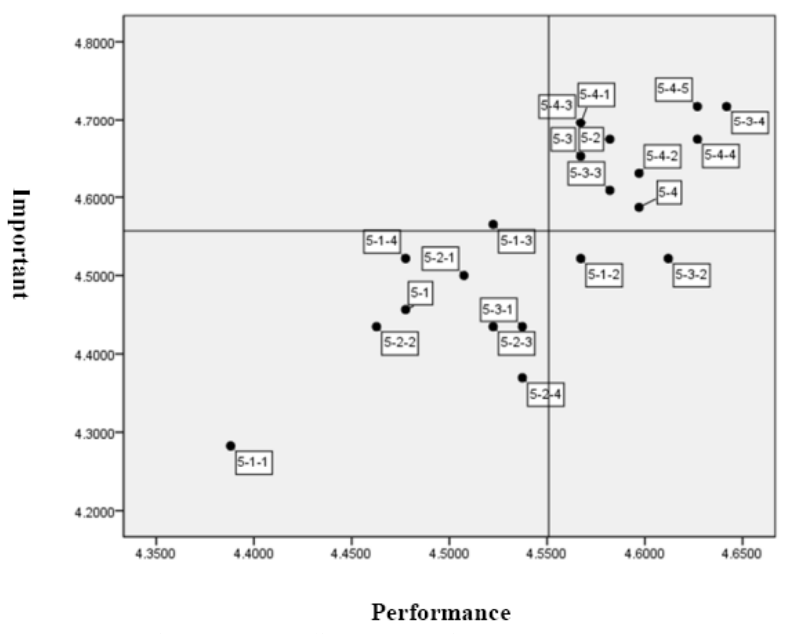

Fig. 5. Responding to questions competence.

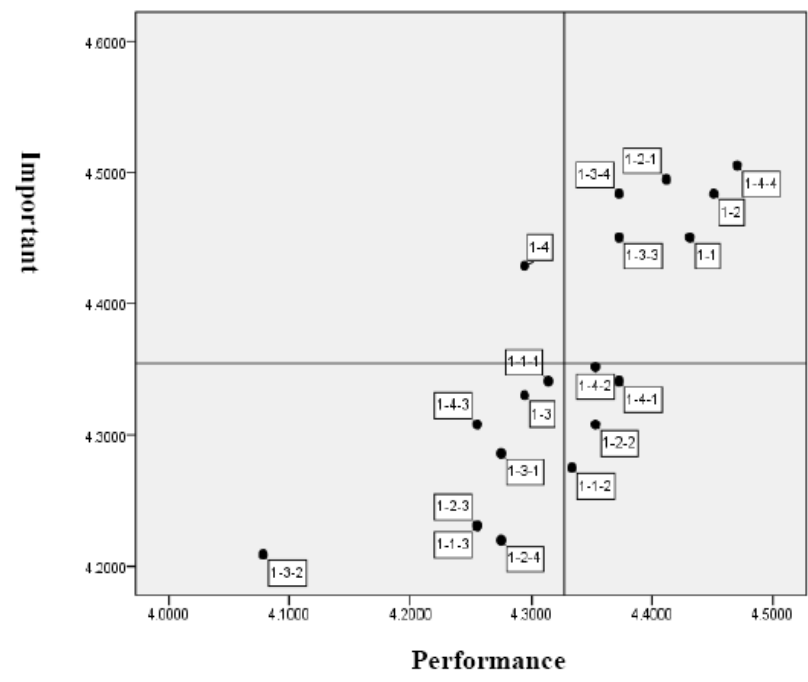

Fig. 6. Inquiring research questions competence.

In the first dimension: inquiring research questions competence (0.087), active inquiring competence (0.186), project study demonstration competence $(0.401)$, writing 
project study research report competence (0.198), oral presentation and responding to questions competence (0.128) Inconsistency=0.06. According to the comparison of evaluating indicators' weight of importance, project study demonstration competence $(0.401)$ is most valued in this dimension. The weight of importance and order of second level dimensions and third level sub-indicators, show as Table I.

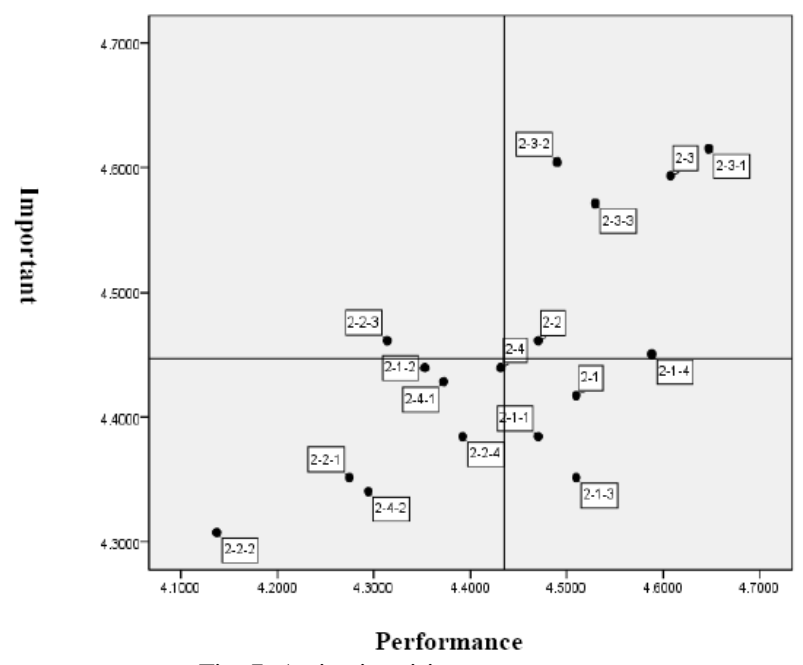

Fig. 7. Active inquiring competence.

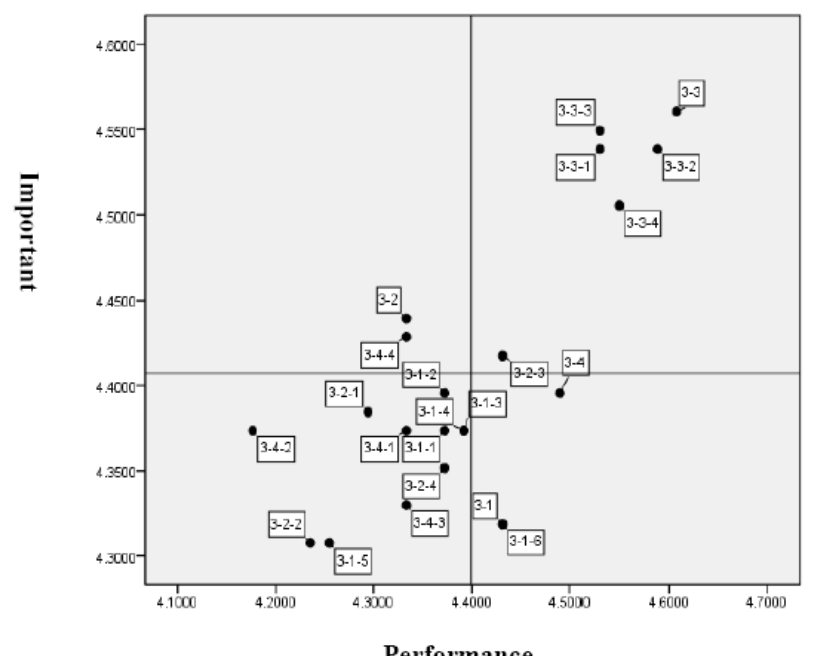

Fig. 8. Project study demonstration competence.

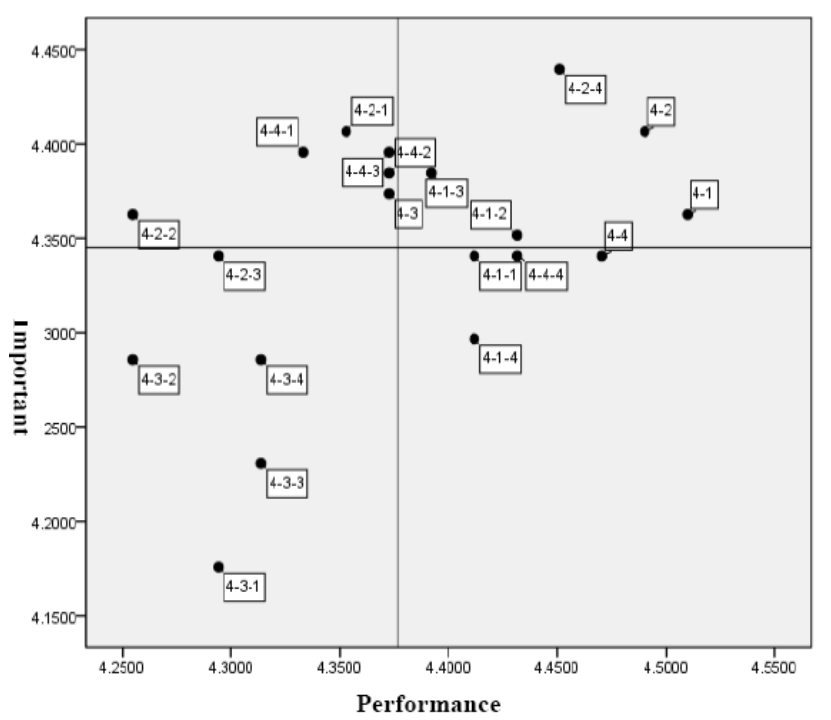

Fig. 9. Writing project study research report competence.

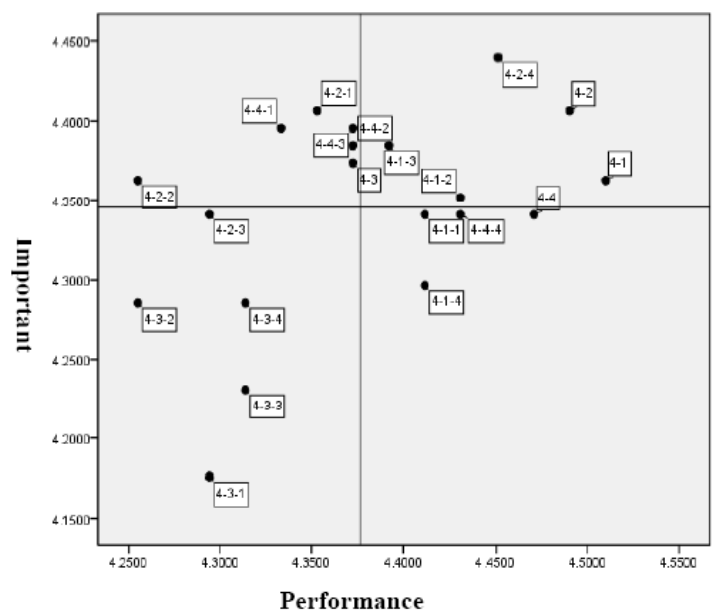

Fig. 10. Responding to questions competence.

In each competence indicator dimension, if the level of importance identified by experts is the highest combining with award-winning students' high perceptions on those competence indicators as well as their capability of being able to achieve them, including problem- identifying competence, team work cooperation and problem-solving competence, good negotiation and communication for problem-solving in the teams, team-work negotiation and cooperation presented through PowerPoint, students' IPA results fall on the first area. Then those competence indicators are suggested as important competence indicators for students at vocational schools when conducting project study.

In this study, the research population consisted of a total of 255 sophomore and junior in the 2013 academic year, including 113 students who had won prizes in the project study related contests, and 142 students who had participated in those contests but had not won prizes. The study conducts Important-performance analysis on five dimensions: inquiring research questions competence, active inquiring competence, project study demonstration competence, writing project study research report competence and oral presentation and responding to questions competence. This chapter is divided into two parts. One is the exploration on five dimensions of students who had won prizes in the project study related contests, as in Fig. 1 inquiring research questions competence, Fig. 2 active inquiring competence, Fig. 3 project study demonstration competence, Fig. 4 writing project study research report competence, Fig. 5 responding to questions competence. The other is the exploration on five dimensions of students who had participated in those contests but had not won prizes, the result in shown in the following figures: Fig. 6 inquiring research questions competence, Fig. 7 active inquiring competence, Fig. 8 project study demonstration competence, Fig. 9 writing project study research report competence, Fig. 10 responding to questions competence.

Fig. 1 to Fig. 5 showing five dimensions of students who had won prizes in the project study related contests. Fig. 6 to Fig. 10 showing FIVE dimensions of students who had participated in those contests but had not won prizes.

\section{CONCLUSION}

Integrating inquiry-based learning into students' project 
study can train and foster students' ability in doing scientific inquiry. Through active learning process, motivate students to learn, and reinforce their abilities in experimental operation and practical skill [13]-[15]. However, as the study discovers, what instructor and the students focus on inquiry learning process are not totally the same. Relative researches also point out the factors which might affect the implement of inquiry-based learning, for example, class size, examination stress, the limit of software and hardware(laboratory equipment, instructional media, for instance), supports from administration, teachers' beliefs and professional competences [17]-[19].

In addition, inquiry-based learning often involves students working in pairs or groups. As it spends much more time than lectures, teachers are under the pressure of teaching progress. Also, teachers might be deficient in related knowledge and experience, which lead to the lack of confidence in implementing inquiry-based learning. These are factors affecting inquiry-based learning. To overcome these difficulties, the study provides recommendations for the Ministry of Education, for teachers and for future research and practice. The study is expected to overcome the difficulties of implementing inquiry-based learning. Through integrating inquiry-based learning into students' project study, foster students' abilities in creative thinking, problem solving, adopt social changes and self-development, in response to the spirit of scientific inquiry which White Paper on Scientific Education and White Paper on Human Resource Development emphasize on.

\section{RECOMMENDATIONS}

\section{A. Implications for the Ministry of Education (MOE)}

There are two recommendations. First, the course of project study is confined to the current teaching method, as well as under the pressure of teaching progress and examination stress, which makes it difficult to integrate with industry. If the integration is achieved and makes it a part of competence indicators, the research would get more sustainable value. Second, the ineffective on implement inquiry-based learning might be a result of teachers' deficiency in related knowledge and experience. To solve the problem, the MOE can organize workshops on project study and competencies in curriculum development regularly. Also, the MOE can encourage teachers to implement action research and to be seed teachers. Through holding workshops in northern, central, and southern parts of Taiwan, teachers can gain more competences on instructing students on project study through the sharing of seed teachers. This way is expected to make teachers encourage students to learn actively in project study, and reinforce their abilities in experimental operation and practical skill.

\section{B. Implications for Teachers}

Based on IPA results, the present study indicated the areas in which students should make improvements. Teachers are encouraged to understand students' perspectives in terms of each dimension and further discuss the indicator items for improvements for better their teaching. Moreover, teachers are encouraged to participate in related programs and course competence seminars organized by Chemical Cluster Departments. Through further training, teachers can be empowered to understand how to implement students' inquiry-learning and enhance their teaching techniques, such as guiding students to explore questions and how to lead students construct good-organized questions [11] so that students could develop their question-model and guide students to learn how to learn. Teachers are also suggested to provide verification inquiry, structured inquiry, guided inquiry and open-ended inquiry based on students' individual differences [20] to construct an interactive and active learning environment for learners [7]. So that students can be guided to conduct inquiry-learning activities and make good use of inquiry techniques and cooperative learning [2]. In addition, teachers could notice the instruction they provide to students. A good instruction should be able to increase students' ability of independent thinking and reasoning. As a scaffolding, it should foster students' learning motivation and recognition [12]-[15].

\section{Implications for Future Research and Practice}

The study aims to construct competence indicators by integrating inquiry-based learning into students' project study in Chemical Engineering Cluster at vocational high schools. Further research can focus on increasing objects of research population into all students in vocational high schools in Taiwan, and analyze the result from the perspectives of different clusters. Then, contrast the difference in constructing competence indicators in different clusters. Also, possible factors which affect the result can be explored. In addition, further research can be conducted by implementing action research, analyze whether there is a difference between students' learning results before and after conducting inquiry-based learning. If there is a difference, analyze what the difference is. With the further discover, the research result would get more sustainable value.

\section{ACKNOWLEDGMENT}

The project was funded by the Ministry of Science and Technology under Grants MOST103-2511-S-018-018.

\section{REFERENCES}

[1] R. W. Bybee, Teaching Science as Inquiry, Washington, DC American Association for the Advancement of Science, 2000.

[2] J. Krajcik, S. Jackson, and E. Soloway, "Model-it: A design retrospective," Innovations in Science and Mathematics Education: Advanced Designs for the Technologies of Learning, New York Lawrence Erlbaum Associates, 2000.

[3] National Science Education Standards, National Research Council, Washington DC: National Academy Press, 1996.

[4] S. Dasgupta, Technology and Creativity, New York: Oxford University Press, 1996.

[5] E. Zimmerman, "It takes effort and time to achieve new ways of thinking: Creativity and art education," The International Journal of Arts Education, vol. 3, no. 2, pp. 74-87, 2006.

[6] M. Csikszentmihalyi, "Social, culture, and person: A system view of creativity," The Nature of Creativity, NY: Cambridge University Press, 1996, pp. 325-339.

[7] S. U. Yeh, "The development of technological creativity indicators for vocational high school students," Taiwan Social Sciences Citation Indicators (TSSCI), vol. 53, no. 3, pp. 67-93, 2008.

[8] R. Sylwester, A Celebration of Neurons, Alexandria, VA: Association for Supervision and Curriculum Development, 1995. 
[9] M. Barak and N. Goffer, "Fostering systematic innovative thinking and problem solving: Lessons education can learn from industry," International Journal of Technology and Design Education, vol. 12, no. 3, pp. 227-247, 2002.

[10] C. H. Hsiao, "Science learning motivation and creative parenting effects on student technological creativity," Journal of Research in Education Science, vol. 57, no. 4, pp. 103-133, 2012.

[11] P. L. Smith and T. J. Ragan, Instructional Design, 2nd ed., Norman, OK: The University of Oklahoma, 1999.

[12] B. R. Belland, C. M. Kim, and M. J. Hannafin, "A framework for designing scaffolds that improve motivation and cognition," Educational Psychologist, vol. 48, no. 2, pp. 243-270, 2013.

[13] S. Khan, "Model-based inquiries in chemistry," Science Education, vol. 91, no. 6, pp. 877-905, 2007.

[14] H. Gardner, Frames of Mind: The Theory of Multiple Intelligence, New York: Basic books, 1983.

[15] F. Abd-El-Khalick, S. BouJaoude, R. A. Duschl, A. Hofstein, N. G. Lederman, R. Mamlok, M. Niaz, D. Treagust, and H. Tuan, "Inquiry in science education: International perspectives," Science Education, vol 88, no. 3, pp. 397-419, 2004.

[16] B. R. Belland, "Scaffolding: Definition, current debates, and future directions," Handbook of Research on Educational Communications and Technology, New York, NY: Springer, 2004.

[17] D. Y. Dai, K. A. Gerbino, and M. J. Daley, "Inquiry-based learning in China: Do teachers practice what they preach, and why?" Frontiers of Education in China, vol. 6, no. 1, pp. 139-157, 2011.

[18] G. B. Esquivel, "Teacher behaviors that foster creativity," Educational Psychology Review, vol. 7, no. 2, pp. 185-202, 1995.

[19] Y. L. Chu, "A study on the relationship between learning attitudes and mathematics academic achievements of Junior high school students," National Digital Library of Theses and Dissertations in Taiwan, 2006.

[20] R. J. Rezba, T. Auldridge, and L. Rhea. (1999). Teaching and learning the basic science skills. [Online]. Available: www.pen.k12.va.us/vdoe/instruction/TLBSSGuide.doc

[21] A. L. Brown and J. C. Campione, "Guided discovery in a community of learners," Classroom Lessons: Integrating Cognitive Theory and Classroom Practice, Cambridge, MA: MIT Press/Bradford Books, 1994, pp. 229-270.

[22] P. Y. Liu and H. C. Chien, B. F. Jones, C. Rasmussen, and M. Moffitt, Real-Life Problem Solving: A Collaborative Approach to Interdisciplinary Learning, Taipei: Higher Education, 2003.

[23] D. C. Edelson, D. N. Gordin, and R. D. Pea, "Addressing the challenges of inquiry-based learning through technology and curriculum design," Journal of the Learning Sciences, vol. 8, pp. 391-450, 1999

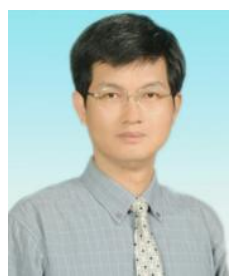

Chin-Wen Liao received both his M.S. and Ph.D. in industrial education from National Taiwan Normal University, Taiwan, R.O.C. in 1994 and 2002, respectively. Since August 2011, he has been a professor in the Department of Industrial Education and Technology at National Changhua University of Education (NCUE) in Taiwan, R.O.C. He teaches courses in technology and vocational education, energy education, course and teaching, organizational learning. His research interests include technology and vocational education, teacher education, energy education of technology, and learning organization.

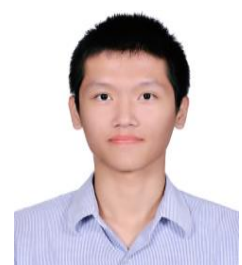

Yu-Cheng Liao graduated from National Taichung Industrial Vocational High School, and now is studying in National Taiwan University of Science and Technology. He did a research with Professor Liao in high school, and one of the researches he did with his colleagues won the National Exhibition of Science and Technology competition. His research interests include science, technological and vocational education, teacher education, energy education of technology, electrical engineering, and learning organization.

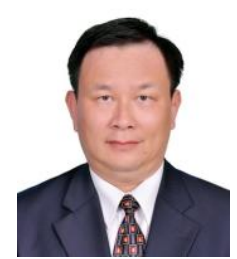

Yao-Tsung Chiang received his M.S. degree in agricultural machinery engineering from National Chung Hsing University in 2002, and currently he is a doctoral student of the Department of Industrial Education and Technology at National Changhua University of Education (NCUE). Since August 2009, he had been the principal of National Chia-Yi Industrial Vocational High School until 2013, then transferred to be the principal of National Wufeng Agricultural and Industrial Vocational High School. Since August 1984, he has taught courses in agricultural machinery, mechanical drawing, introduction of computer science, frozen food machinery and introduction of machinery in National Yuanlin Agricultural and Industrial Vocational High School until 2009.

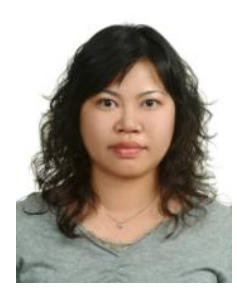

Hui-Fen Wu received the B.S. degree at the Department of Chaoyang University of Technology in 2002, and currently is a M.S. student at the Department of Industrial Education from National Changhua University, Taiwan, R.O.C. Since August 2014, She has as a business marketing post of manager in Taipei Wu-nan Culture Enterprise, be responsible for the senior high schools textbook publication marketing work.

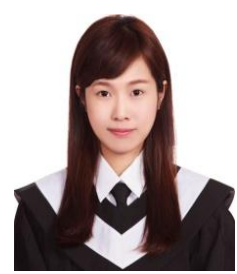

Yun-Hua Liao graduated from National Taichung Girl's Senior High School, and now is studying in the Department of Civic Education and Leadship, National Taiwan Normal University. She did a research with Professor Liao in College, and continue participate higher education research. Her research interests include technological and vocational education, teacher education, energy education of technology, public policy, civic education \& leadship, and learning organization. 